\title{
A NEW METHOD OF TREATMENT FOR SUPPURATIVE ARTHRITIS OF THE KNEE-JOINT.
}

\author{
By Ma.JoR J. EVERIDGE, R.A.M.C. T.
}

Current Methods of Treatment.-In spite of the dramatic progress in the surgical treatment of penetrating gunshot wounds of the knee, suppurative arthritis of this joint, when it occurs, has remained a condition often defeating our most painstaking endeavours.

Its treatment has been attempted by both surgical and chemjcal methods, the former having for their object joint drainage, the latter aiming at the destruction of bacteria by the application of one or another antiseptic. That joint drainage by purely operative measures is unsatisfactory is manifest from the multiplicity of methods which have been described from time to time. Anterior and posterior incisions, the turning up or turning down of a patellar flap, joint resection-all have had their adherents. The drainage tube inserted in the interior of the joint has long since been discarded. Similarly, the diversity of the antiseptics that have been used indicates the uncertainty of the action of each one of them. Either it is too irritating and still further lowers the vitality of the articular components already almost overcome by the septic processes, or, if it is non-irritating, its germicidal effect is so weak as to make its use of doubtful value. Further, to diffuse the antiseptic to all the numerous articular recesses where the germs lie hid is, in practice, impossible. The ideal antiseptic, in fact, has not yet been discovered.

After operating upon penetrating knee-joints, it has been almost the universal practice among British surgeons working in the war areas to adopt strict immobilization in the Thomas splint for at least ten days, and often much longer, after the temperature has settled.* Should suppuration occur, complete immobilization has been, more than ever, the unchallenged principle in treatment.

Disadcantages of Prolonged Immobilization.--I wish to draw particular attention to the fact that a limb long maintained at rest not only suffers muscular atrophy, but, worse, is also largely deprived of its blood-supply. The contracted state of the large arteries of the leg to be noticed when amputating a limb long immobilized is evidence of this. Further, elementary physiology teaches us that muscular action promotes the flow of blood in the veins. Finally, those experienced in war surgery are familiar with the frequency of tracking sepsis in legs where, for some reason or another, the main artery has required ligature. To illustrate this, I quote a series of 23 suppurating cases treated by me in 1917-18 by most careful immobilization with extension in suspended Thomas kneesplints ; tracking took place in 17. In some, the pus tracked almost to the extremities of the limb. Four of these cases subsequently came to amputation (one in France and three in England). These facts make it appear reasonable to reconsider the advisability of complete rest in the management of such cases.

A Physiological Method of Treatment.-Realizing how great are the natural powers of resisting infection possessed by the joint, I have endeavoured to evolve a method of treatment wherein they are utilized to the utmost. I have ventured to call this system

* An article ${ }^{1}$ I published in the British Medical Journal, August 24, 1918, calls attention to the tendency to employ splints for unnecessarily long periods of time. It suggests a method where, by carrying out passive mobilization at first, a wide range of movement may be established with the least risk of " stirring up sepsis and breaking down healing tissues in and round the joint, while at the same time the formation of anchoring
adhesions is prevented. 


\section{SUPPURATIVE ARTHRITIS OF THE KNEE}

of dealing with an infected joint the 'physiological method,' for the natural processes of repair enter largely into its rationale.

This alternative treatment which I am recommending is consistent with physiological and pathological axioms, though in disagreement with the well-known doctrines of Hilton. It relies for its curative effect on active movements of the joints of the lower extremity, including the knee. It must be emphasized, however, that adequate openings into the infected joint must first have been established to allow the free escape of synovia and pus ; otherwise, movement will result in the dissemination of sepsis into culs-de-sac of the joint and extra-articular muscle planes.

Active movement of the joint will be begun soon after it has been operated upon, and is regulated under the supervision of the surgeon in charge or his assistant. The rationale of the procedure may advisedly be explained to the patient, who, realizing what is required, will usually lend his full co-operation. Still more will he do this when experience shows him that movements actually alleviate pain, coincident with the visible escape of pus from the joint. Active movements of not only the knee-joint but also the ankle are advisable, for the resulting contractions of the leg muscles will hasten the venous flow, thus diminishing capillary stasis, as evidenced by the absence of odema of the foot.

To sum up, the advantages to be derived from treatment by early active mobilization appear to be five, its effects being :-

(1.) To hasten repair by the preservation of a good blood-supply to the tissues of the affected joint.

2.) To aid drainage, as Willems ${ }^{2}$ has emphasized.

3. To prevent extreme atrophy of the muscles, so that these will be better able to resume function when the articular inflammation is at an end.

7. To establish a process of auto-vaccination.

5. To realize the possibility of a subsequently mobile joint.

On the other hand, experience has shown that the treatment is not advisable in cases with gross injury to the articular bone or essential tendons or ligaments; or where suppuration in the joint has gone on for sixteen days or more.

\section{THE SYNOVIAL FLUID.}

The synovial fluid in the knee-joint is of such importance in the method of treatment I am advocating, that it is worth while to discuss its nature and modes of reaction to infection in detail.

\section{Bacterial Invasion.}

1. In 70 to 80 per cent of the cases of penetrating wounds of the knee-joint, this fluid at the original operation shows that 'soiling' has occurred. In most it is not possible to see and recognize organisms in it ; only on cultural examination can their presence be determined.

2. Where the 'toilet operation' has been successful, these organisms disappear. Subsequent effusion, should it occur, is found to be sterile.

3. Where the 'toilet operation' has failed, as rendered apparent by the persistence or recurrence of the clinical signs of inflammation more than four days after operation, bacteriological examination reveals organisms in profusion by both direct and cultural methods.

According to Sacquêpee (quoted by Gosset ${ }^{3}$ ), in the first few days after joint penetration the number of visible germs in the articular effusion is appreciably less than in wounds of bone or muscle It is even the rule that in the first twenty-four hours direct examination reveals no organisms. Cultures, however, demonstrate their presence even when the examination is practised very soon after the wound. Where circumstances permit of further examinations, it is almost always found that there is a multiplication in germs up to about the sixth day, when symptoms of infection begin to arise.

The Cellular Elements.

1. At the original operation the identification of cells typical of inflammation voL. VI.--No. 24 . 
is generally prevented by the presence of red and white blood-cells resulting from a hæmorrhage into the joint.

2. In the absence of such a hæmorrhage, a preponderance of leucocytes is not pathognomonic of severe septic infection of the joint.

3. A differential leucocyte count affords evidence in determination of infection. An 80 per cent polynuclear count marks roughly the dividing line between good and bad prognosis (Lazarus Barlow ${ }^{4}$ ).

4. The presence of extracellular organisms and the absence of phagocytosis, when suppuration has lasted for ten days, point to a severe infection and limitation of powers of resistance. Too much reliance, however, should not be put upon this observation.

The following changes in the nature of the fluid escaping from a joint, during the progress of suppurative arthritis, to a certain extent reflect the clinical evolution of the intra-articular inflammation. Three stages may be recognized:--

A. Developing.

1. (a) Synovial fluid discoloured by altered blood; (b) Albuminous fluid like coagulating white of egg.

2. Sero-purulent fluid.

B. Established Suppuration.

3. Pus. (a) Thick and creamy in staphylococcal infection; (b) Thinner and less viscid in streptococcal infection.

C. Subsidence.

4. Pus with semi-solid curds.

5. Curds floating in a clearer fluid.

6. Synovia, clear and limpid.

The appearance of the last two types of escaping fluid is valuable as evidence of resolution of intra-articular inflammation. Histologically, the last reveals few polymorphonuclear cells and, as a rule, no extracellular organisms, the few bacteria present being intracellular.

(At this stage, should large open wounds be present with healthy vascular granulations, and if no pus is apparent, either as a secretion of the granulating surface or escaping from a sinus leading to necrosed bone, it is safe to carry out partial or complete secondary suture. This step is advisable, for dense cicatrices, which are subsequently of considerable inconvenience, may best be avoided by early suture.)

Synovial Fluid as a Natural Germicide.-A joint subjected to an irritant, whether mechanical, chemical, or bacterial, reacts by an inflammation of the synovial membrane and the outpouring of an excess of synovial fluid into the articular cavity. In which articular components do the germicidal properties chiefly reside? The only three tissues which can supply this protection are :

(1) The synovial membrane ; (2) The synovial fluid; (19) The cartilage (either the menisci or that clothing the bone).

On account of the avascularity of the third, only limited powers of resistance can be ascribed to this structure. The synovial membrane, on account of its good blood-supply, should be competent to protect itself.

The most valuable germicidal agent of the joint must be the synovial fluid. This, after all, is but slightly altered from blood plasma, and no doubt is endowed with all the protective qualities which the blood itself possesses. We should expect to find that the protective value of it would vary directly as the supply of freshly oxygenated blood. The supply is largely governed by muscular action, involved in active movements. A flushing of the interior of the joint with fresh synovia, especially the more vulnerable components, such as the cartilages, $I$ believe to be a factor of importance in the natural recovery from joint infection.

Sacquépée's observations, mentioned already, coincide with the opinion held by Veillon, ${ }^{5}$ who regards synovia as being powerfully germicidal provided that it is freshly secreted; if allowed to stagnate, it loses this property, and becomes instead a good culture-medium for bacteria. 
It appears probable that the operation of paracentesis followed by the injection of an antiseptic fluid, referred to by Lockwood ${ }^{6}$ and others, owes its success in arresting sepsis in certain early cases of suppurating knee-joints to the withdrawal of synovial fluid rather than to the antiseptic instilled. It is not easy to see how a solution such as 2 per cent formalin-glycerin could kill all the germs in an infected joint; many of these lie concealed in synovial recesses and in blood-clot far beyond the reach of any antiseptic injection.

Describing penetrating gunshot wounds of the knee-joint, various observers give the percentage of instances in which 'soiling' of the synovial fluid with organisms has occurred as between 70 and 80 . Where a fragment of high-explosive shell is lodged in the joint, the introduction of germs is bound to have occurred ; yet the vast majority of such cases run an aseptic course after the removal of the foreign body and the performance of a "joint toilet' on the lines so ably laid down by Colonel Gray. ${ }^{7}$ The operation no doubt removes a considerable number of the organisms and infected material ; a large residue, however, must remain, and is dealt with efficiently by the synovial fluid.

In the 20 to 30 per cent of failures, where the mass-action of infection has been too great, and clinical 'sepsis' as distinguished from 'soiling' has occurred, the aim of subsequent treatment will be : (1) To ensure a free outlet for synovia ; (2) To preserve the best possible blood-supply to the joint structures; and, as a corollary, (3) Thereby to provide a supply of the healthiest synovial fluid, that is, synovia best equipped with vigorous phagocytes and antibodies.

\section{PRACTICAL DETAILS OF THE PHYSIOLOGiCal METhOD.}

The Formation of Adequate Joint Stomata by Operation.- The stereotyped vertical parapatellar incisions commonly used for drainage of the knee-joint have the following drawbacks :-

1. Wide gaping of the skin owing to the run of the natural lines of cleavage in this situation. The result is wounds taking long to heal, and ultimately leaving troublesome cicatrices.
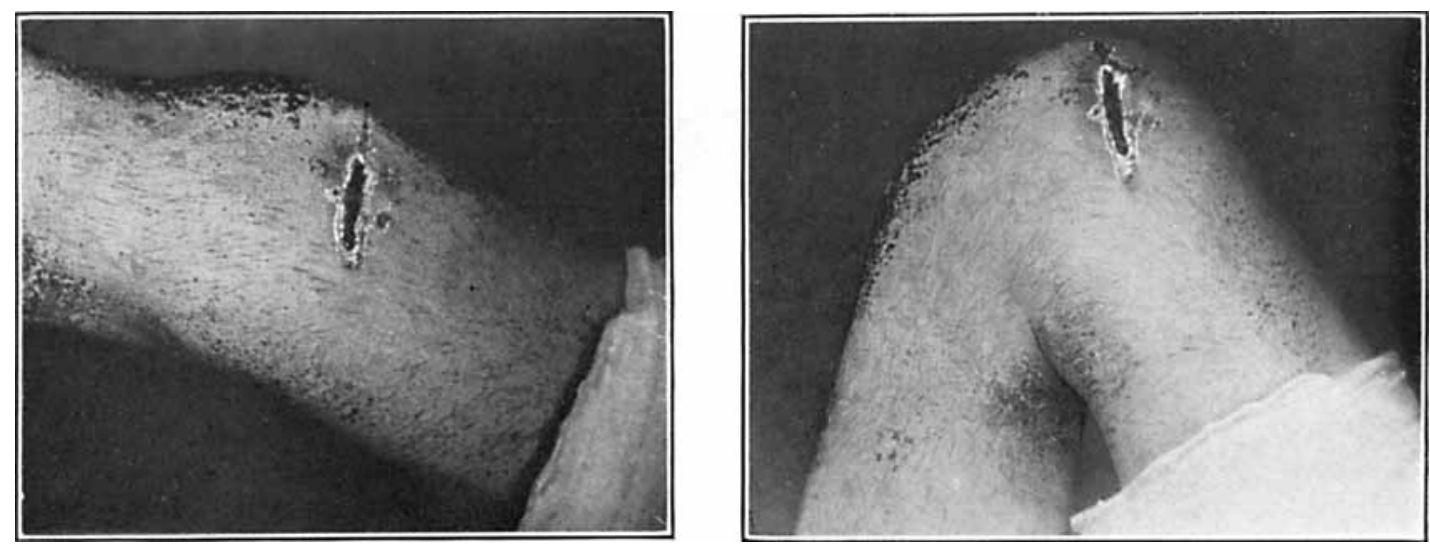

FI(s). 190, 491.-The condition of the transverse arthrotomy incisions, with skin-synovial suture, one month after receipt of the wound, which produced a staphylococeal arthritis.

2. Joint openings which tend to close early, since the split muscle and tendinous fibres forming the capsule fall together spontaneously.

3. Interference with the blood-supply of the patella, since the main vessels, which pass transversely inwards, are divided by these incisions. 
4. Troublesome hamorrhage either at the time of the operation or some hours later. The bleeding vessels shrink away into fibrous tissue when cut, and are difficult to secure.

5. Should amputation subsequently become necessary, the anterior flap is interfered with.

Owing to these drawbacks, I have for some time past been in the habit of using transverse incisions (Figs. 490, 491). These remain open satisfactorily and, where active mobilization is employed, appear to drain the joint just as efficiently as the vertical incisions. They are made from the outer and inner borders of the patella, commencing at
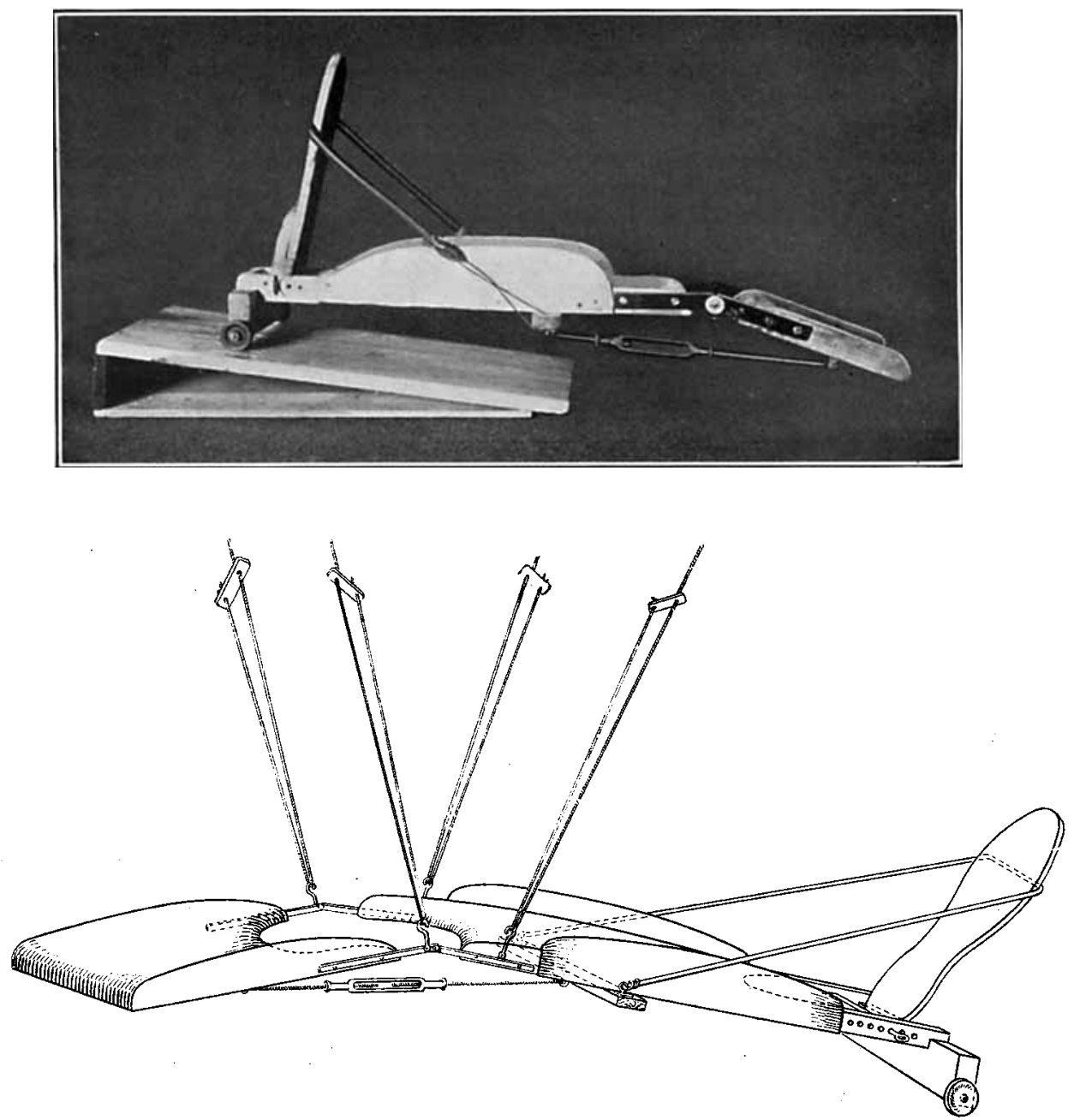

FIGS. 452, 493.- 'Active movement' splint. It can be made rigid by fixation of the adjuster below the knee. Note the adjustable foot-piece, supported by elastic slings.

the junction of the upper and middle thirds of the bone, and continuing for a distance backwards of about an inch and a half. These incisions are far removed from the lateral ligaments, which lie below and behind them. The outer incision partially divides the iliotibial band. 
All structures down to and including the synovial membrane are divided in the line of the skin incisions. As a final step, the cut edges of the synovial membrane are stitched to the cut edges of the skin by a series of suspension sutures. A single layer of rubber tissue is inserted between the lips, and left in situ for twenty-four hours, to prevent the closure of these openings by adhering blood-clot.

If the muscles of the thigh are unusually well-developed and do not retract sufficiently to leave adequate joint openings, an elliptical segment is excised on either side.

Active Mobilization.- To persuade a patient suffering from an early suppurative arthritis of the knee to carry out active movement is, in practice, by no means easy. He is ill, weak from fever and possibly from loss of blood ; and, moreover, his joint is excessively painful. Without some help he will be able to do little or nothing. He cannot raise his leg off the bed, far less bend and straighten the knee. For these reasons $I$ have constructed an apparatus, the description of which follows, by means of which gravity is practically eliminated.

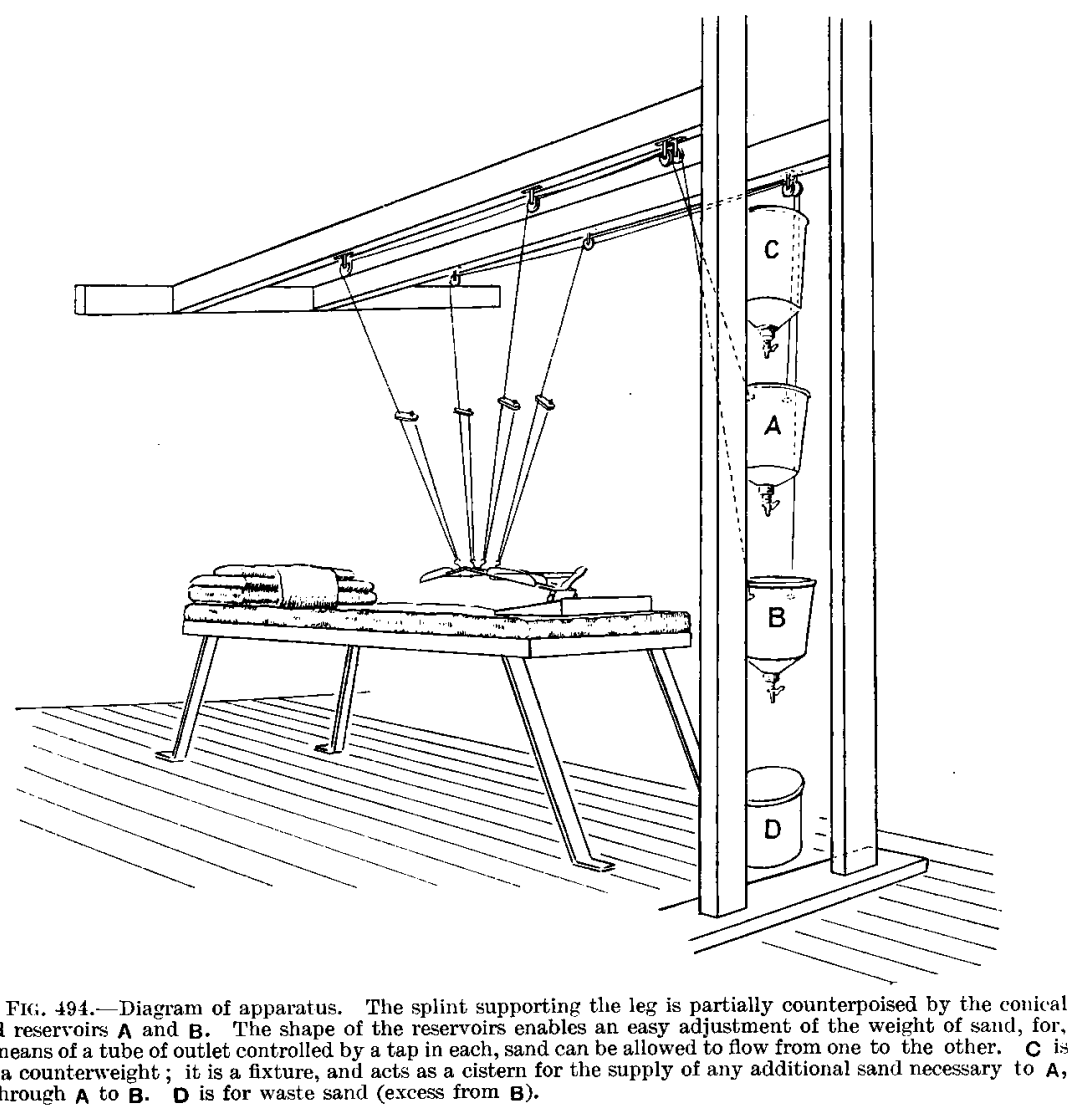

\footnotetext{
FIK. 494.-Diagram of apparatus. The splint supporting the leg is partially counterpoised by the conical by means of a tube of outlet controlled by a tap in each, sand can be allowed to flow from one to the other. $C$ is not a counterweight; it is a fixture, and acts as a cistern for the supply of any additional sand necessary to $A$, or through $A$ to $B$. $D$ is for waste sand (excess from $B$ ).
}

Apparatus,- This comprises : (1) A suitable splint ; (2) An overhead counterpoise system.

1. The Splint (Figs. 492, 493).-This is an elaborated back splint with foot-piece, and possesses the following features :- $(a)$ It is guttered to fit the shape of the leg. (b) It is interrupted, where it lies behind the knee, to give access for inspection and dressings. (c) The metal bars bridging the interval are jointed. (d) An adjuster is fitted like that supplied with the standard McIntyre splint. This is made easily 
detachable; when removed, there is freedom for knee movements. (e) $\mathbf{A}$ footpiece is supplied, adjustable in position according to the length of the leg. It is pivoted on
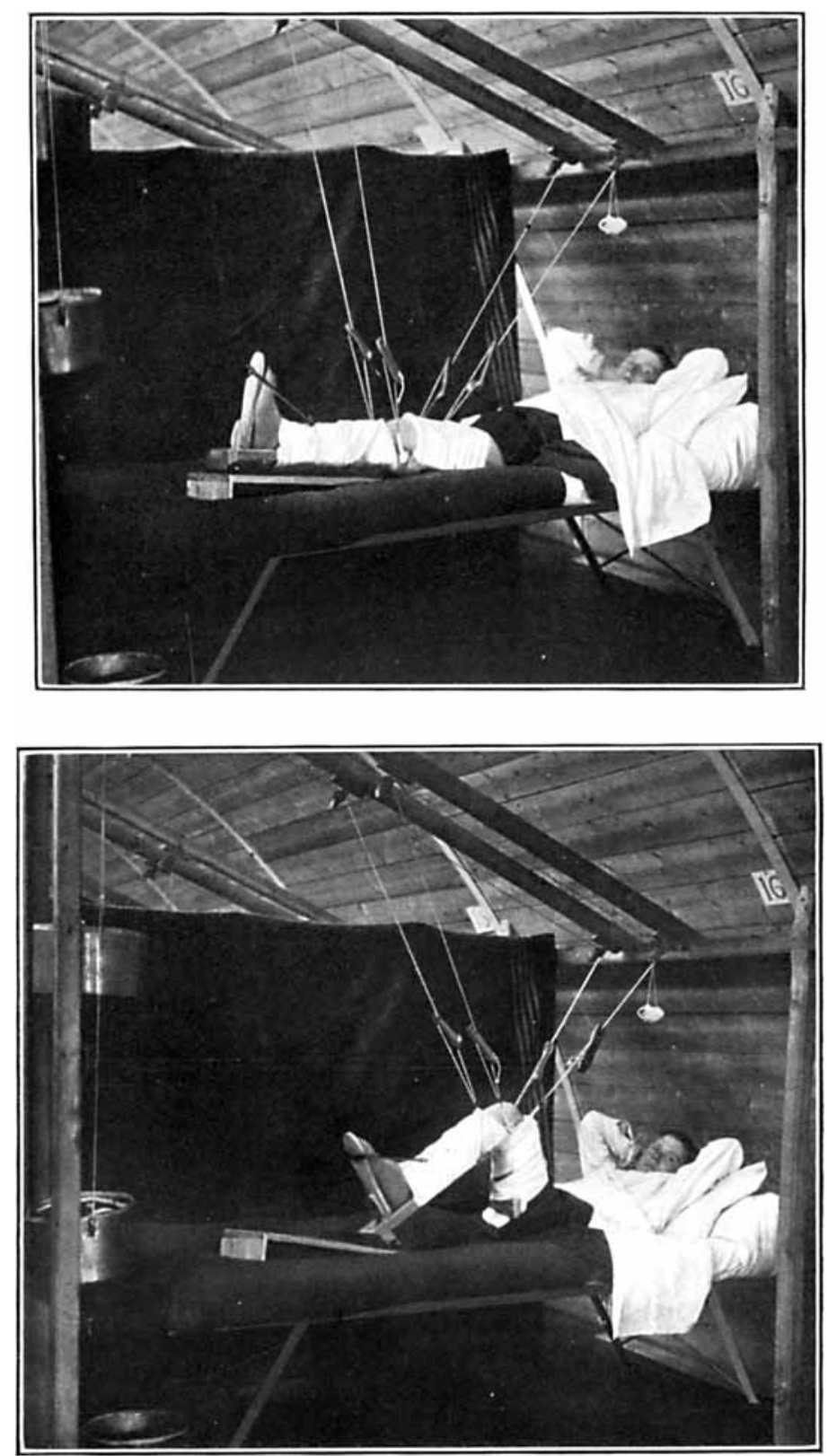

FIfis, 495, 496.-Demonstrating the apparatus in use.

the adjusting pin, and held up by two elastic slings. Thus the foot is maintained in dorsiflexion when at rest. (f) Running wheels are attached below the foot end of 


\section{SUPPURATIVE ARTHRITIS OF THE KNEE}

the splint. These prevent friction, and allow a free excursion up and down a platform on which the splint rests.

2. The Counterpoise System (Figs. 494, 495, 496). - That shown in the accompanying figures may appear somewhat complicated. It is the standard pattern $I$ have established in France for the treatment of suppurative arthritis and other conditions of the knee-joint. It has many practical advantages, but an enumeration of these would somewhat complicate the present consideration.

All that is really essential is four pulleys attached somehow above the leg. These transmit four cords, two of which are attached just above, and two just below, the hinges of the splint. At their other ends are fixed counterweights (sandbags, etc.). These are not quite heavy enough to suspend the leg in the air. They merely serve to overcome most of the force of gravity. With this arrangement the patient's limited energy may be economically spent on movements at the knee, and not wasted on the purposeless act of lifting the leg from the bed.

Active movements are at first carried out under the observation of the surgeon or his trained assistants. The splint is fixed by re-applying the screw adjuster at all times when jars, twists, or strains might occur, such as during sleep, nursing procedures, etc. Experience shows that normal movements of flexion and extension are singularly painless provided there is a free outlet for fluid from the joint, preventing any rise in intra-articular tension.

Patients soon become interested in the routine, and enjoy considerable relief of pain when the daily movements are carried out. In fact, they often ask that the splint may be released, in order to ease their discomfort by movement. Emphasis is again laid on the importance of movements of the foot. Active contractions of the muscles of the leg stimulate the flow of blood and prevent the occurrence of œdema from venous stasis. Possibly, also, contractions of the gastrocnemii help to massage up pus from the posterior compartments of the knee-joint.

The physiological method, in order to be of service, must be instituted early. It is useless to commence it when all the joint structures are becoming disintegrated by septic processes, and especially when the cartilages are becoming eroded.

For this reason I believe it unwise to resort to the operation of arthrotomy, lavage, and closure, where signs of sepsis occur as late as a week after the date of the original wound or primary operation. It is wiser to avoid the waste of time incurred by this operation, which, more often than not, fails to arrest sepsis at so late a stage. Fach day's delay renders the mobilization method less likely to succeed, and lessens the chance of obtaining a movable joint at the finish.

\section{Particulars OF CASES.}

To illustrate the type of case which lends itself to this method of treatment, the following may be quoted as good examples :-

Case 14.--L.-Cpl. T. Received a shell wound of right thigh and knee, Oct. 15, 1918 . At the casualty clearing station a piece of high-explosive shell was removed from the extensor muscles just above the outer angle of the patella. The wound was excised and sutured ; the knee-joint at this operation did not appear to be involved. The patient was admitted under my care on Oct. 17. On Oct. 21 the knee was painful and slightly swollen, the temperature $100^{\circ}$. On paracentesis the following day, turbid coagulating fluid was withdrawn from the joint. Histologically examined, this was seen to be rich in pus cells and staphylococci. In consequence, the wound was reopened, internal transverse arthrotomy (by the method described above) was done, and the joint washed out with saline. Immediate active mobilization was instituted. Movements were good from the first, and the temperature and pulse settled in the course of a few days. On Nov. 4 active flexion could be carried out through a range of $100^{\circ}$, and by this time the fluid escaping from the joint had become clear and limpid, resembling typical normal synovia. Two days later fluid had ceased to escape. By Nov. 18 the wounds were healing well, there was full range of active movement, and the patient was getting up and able to walk a few steps. On Nov. 20 he was sent to England, with the right knee-joint normal to all outward appearances, 


\section{THE BRITISH JOURNAL OF SURGERY}

except for incompletely healed wounds. The accompanying photographs (Figs. 497, 498) show the range of movement thirty days after the receipt of the original injury. Two and a half months from the date of injury, the report from England stated that the wounds were healed, there was full range of movement, no swelling of the joint, and the patient could walk two miles.

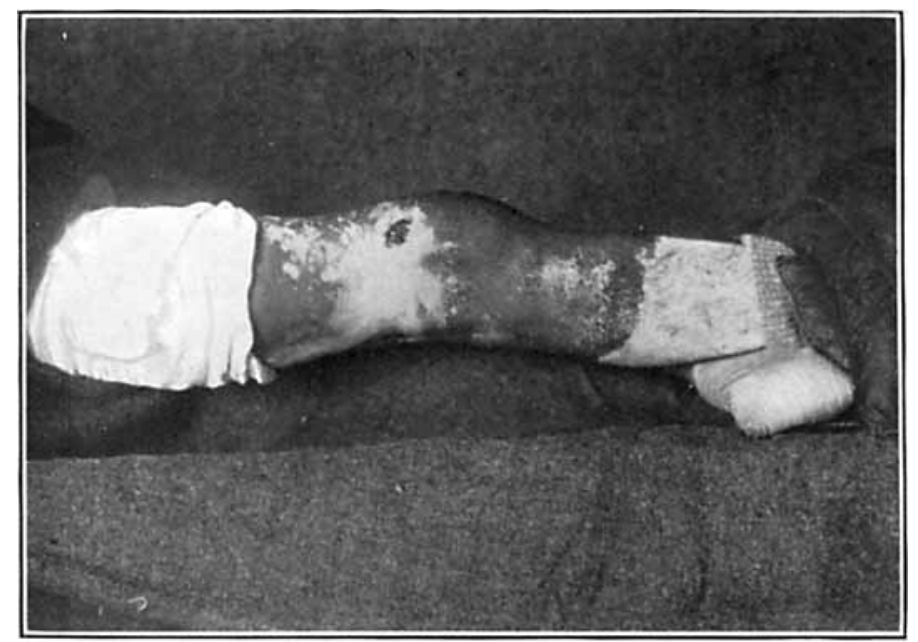

FIG. 497.-Case 14, one month after shell wound of the knee which produced a septic arthritis.

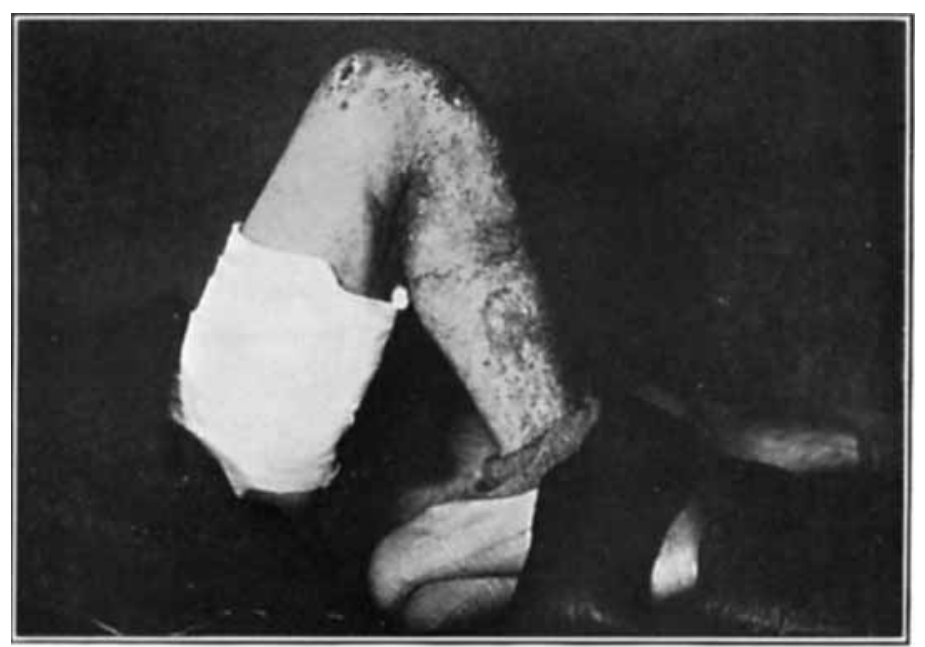

FrG. 498.-The same case, showing that at this time a complete range of movement was possible.

Case 17.-Gnr. D. Received a shell wound of right knee on Oet. 23, 1918. The fragment of shell was removed the following day at a casualty clearing station; the joint was washed out with Dakin's fluid and closed. The patient was admitted under my care on Oct. 25, when the whole joint was very much swollen, the skin was odematous, and there was great tension on the lower stitches of a long antero-internal arthrotomy wound. Some of the stitches were immediately removed. The next day paracentesis was done, and suppurating blood clot removed from the joint. On examination, this fluid contained pus cells, B. Welchii, and staphylococci in profusion. Accordingly the same day an external transverse arthrotomy with skin-synovial suture was done. At the same time the lower part of the original wound, where it lay over the joint, was opened, 
and the skin stitched to the synovial membrane. The joint was washed out with saline, and, of course, left open. In the course of eleven days the temperature had settled and active movement through $82^{\circ}$ was easy. By Nov. 21 there was full range of active movement, and the wounds were granulating well, fluid having ceased to escape from them. On Nov. 25 the patient was getting up and could bear weight on the limb. (See Figs. 499-502). By Dec. 15 he was able to walk long distances without a stick, and there was hardly any perceptible lameness.

In the more virulent types of inflammation, and especially when it is associated with gross bone injury, movements towards the end of the third week may become restricted and painful. If this is not due to a collection of pus in the popliteal space, it is regarded as coinciding with erosion of the articular cartilages, and is the signal for the application of a rigid Thomas splint with extension, hope of a mobile knee being no longer entertained.

Such an occurrence is not to be regarded as complete failure, for experience shows that the measures adopted early have served the following purposes : (1) Prevention of tracking ; (2) Hastening of resolution of the septic processes within the joint

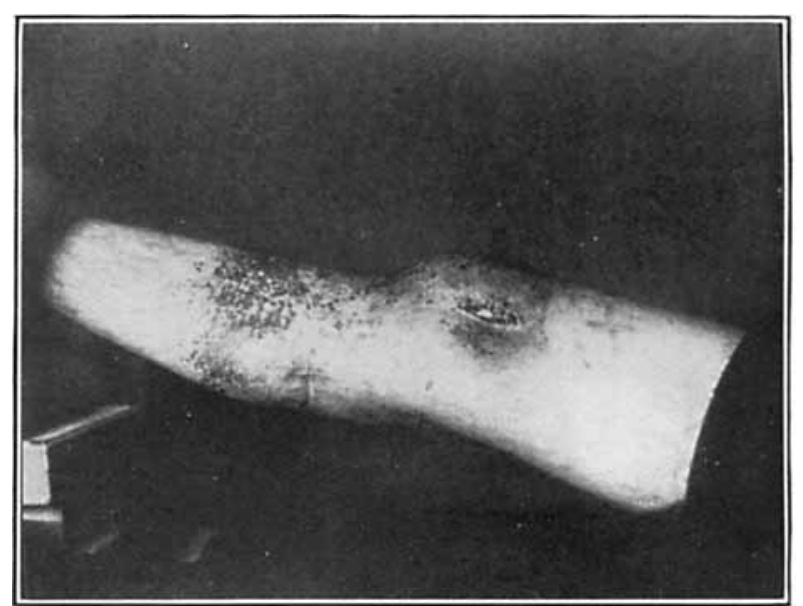

Fis. 499-Case 17, five weeks after remoral of missile which produced a suppurative arthritis (staphylococcus and $B$. Welchii). The lower part of the original operation wound was converted into a joint stoma. by stimulation of the synovial circulation; (3) Limitation of the intensity of the inflammation and of toxic absorption.

Not the least striking feature when this treatment is carried out is the satisfactory

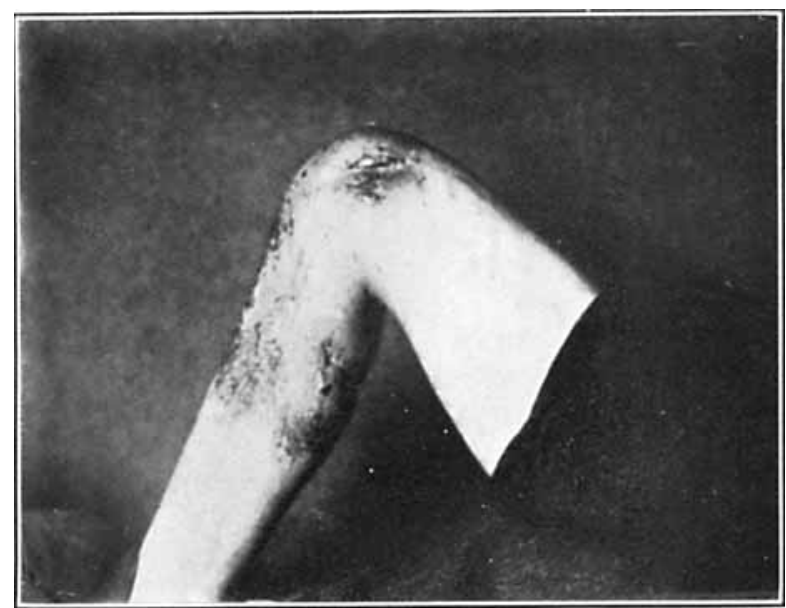

Fic. 500.-The same case, showing range of movement. general condition these patients preserve. Their appetites remain good; they sleep well; take interest in their surroundings ; and, in fact, present an entirely different picture from that which we were accustomed to see when treatmient by immobilization was carried out.

Though the tendency to track is overcome, a localized abscess frequently occurs in the popliteal space.* It is not quite clear whether this comes about by an extension through the back of the joint by way of the bursa, or by a track superficial to the condyles. These abscesses occurred in 10 out of 23 cases treated by the physiological method.

* The occurrence of pain, swelling, and cdema in the popliteal space is an indication for an immediate exploratory incision. 

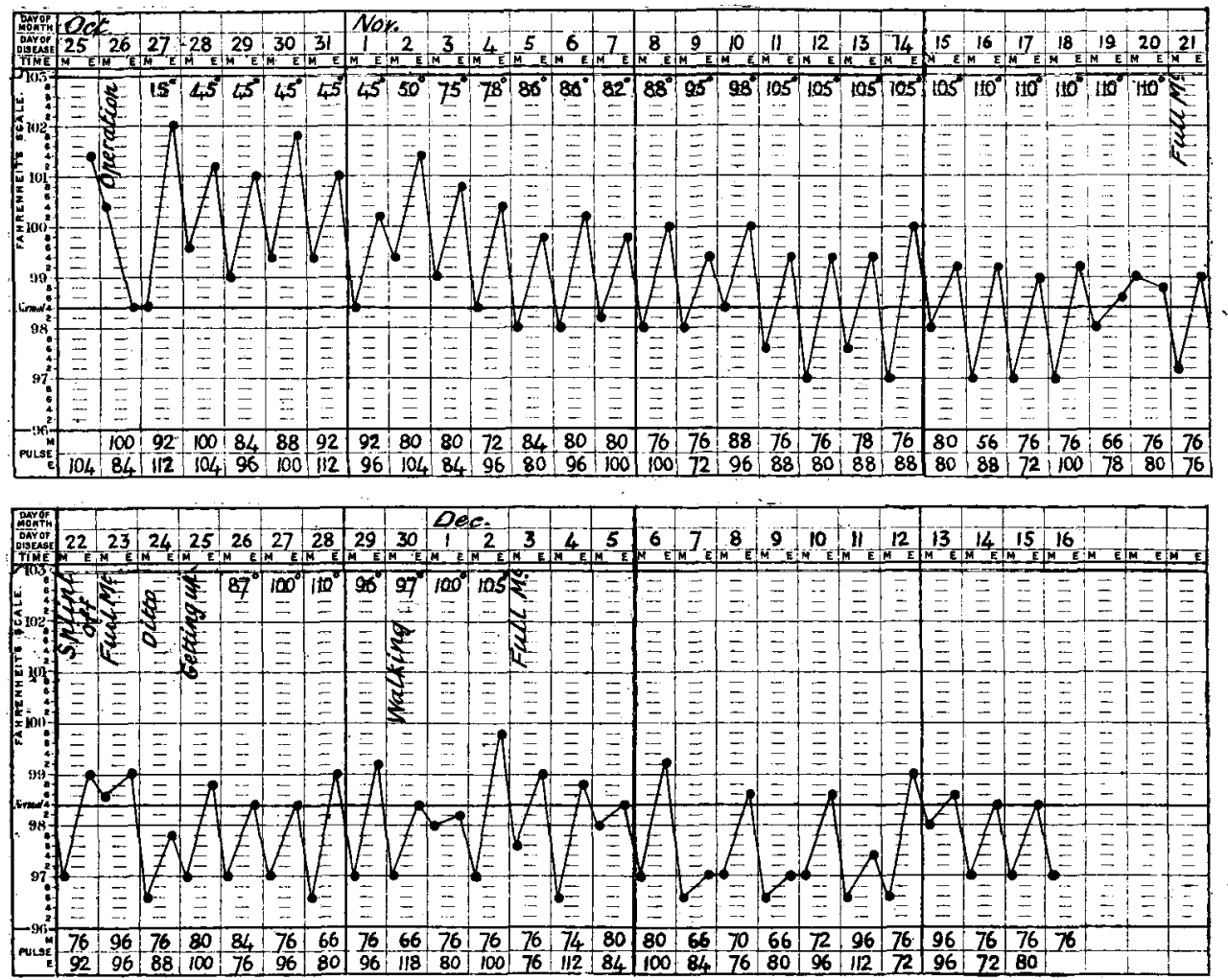

FIf. 501.- Temperature chart of case 17. The increment in range of actire'movemeit is indicated by the number stated in derrees. Note the steady pulse-rate and gradtal subsidence of temperature.

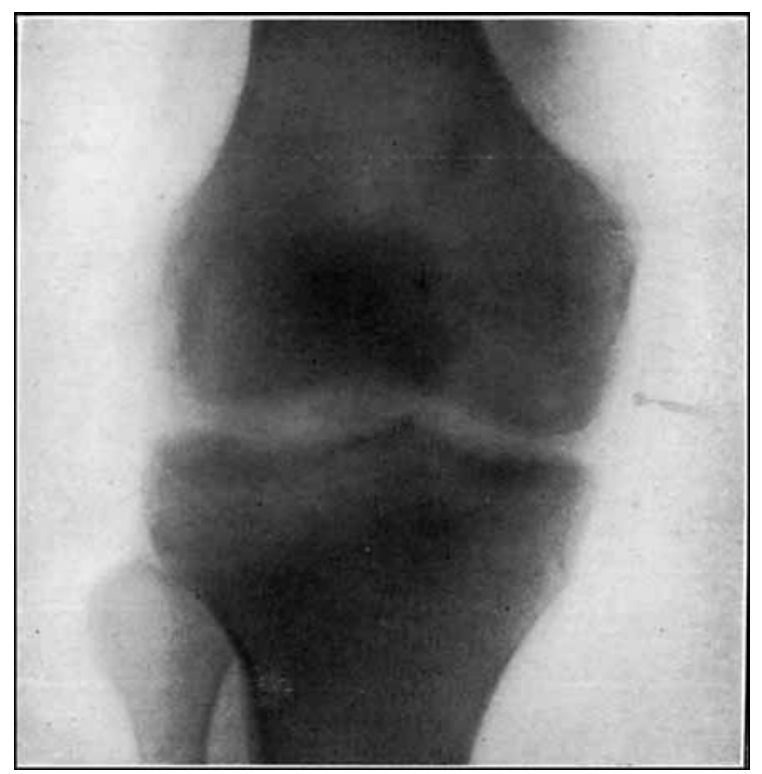

FIG. 00 . - Skiagram of Case 17 at the sixth week. To demonstrate that absorptive changes in the bone are rery limited, extending only a short distance into the depth of the cancellous tissue. There is no subperiosteal deposit of new inone. 
That a joint treated by the physiological method may sterilize itself is evident from the following case :-

Case 8.-Bdr. M. Developed a streptococcal arthritis after a shell wound, which caused a very septic compound fracture of the fibula, and injury to the popliteal artery necessitating its ligature in addition to the joint lesion.

The joint was treated by the physiological method. On the twenty-ninth day it became necessary to amputate, owing to extensive suppuration in the lower part of the leg, the consequence of ligature of its main artery. Examination of the amputated limb showed that the interior of the knee-joint was in a satisfactory state. There was no pus, merely a little clear fluid, upon which the pathological report was as follows : in 50 fieids there were 114 polymorphs, 34 lymphocytes, and 4 cocci.

Such a degree of recovery in a very acute streptococcal joint after twenty-eight days' treatment offers convincing proof of its efficacy. The joint fluid, in fact, revealed a condition of cleanliness which almost conformed to Carrel's standard of 'clinical sterility. ${ }^{8}$

The Table on p. 578 shows that about 50 per cent obtained a mobile knee. There were no deaths in the series, and the one amputation (Case 8) was necessary on account of intractable suppuration in the leg resultant upon ligature of the popliteal artery; the knee-joint, subsequent examination showed, had settled down completely. In each of these cases the knee-joint was definitely infected and in one of the various stages of suppuration; not one was merely a 'soiled' joint. It will be observed that in no instance where movements were commenced after the seventh day did a mobile joint result. Mobilization, however, in these cases undoubtedly served a useful purpose, and the end-results, though ankylosis occurred, were very good.

A practical difficulty lies in deciding upon the length of the period of probation, for in many cases of suppurative arthritis acute symptoms are not manifest until as late as the tenth day, and the fact that effusion into the joint is occurring may escape notice by the leakage of synovial fluid into the depth of an open wound near the joint. Many coincident conditions may be factors in producing pyrexia, increased pulse-rate, and other symptoms of toxic absorption. In some cases-necessarily not included in the foregoing list-the local signs, the symptoms, and the withdrawal of a synovial fluid rich in polynuclear leucocytes have prompted me to adopt the physiological method of treatment without delay, knowing that evidence of the existence of bacteria might require fortyeight hours to be reliable, the time necessary for incubation of organisms dilatory in growth on artificial culture media. In no case where the pathologist's report was subsequently negative for bacteria did contamination of either the stomata or the interior of the opened joint occur, and progress to free mobility was unhindered.

\section{SUMMARY AND CONCLUSIONS.}

1. All surgical methods of draining the knee-joint in suppurative arthritis have certain drawbacks.

2. The physiological method of treatment described above endeavours to provide: (a) A circulation of synovial fluid with maximum powers of resistance, in virtue of a free blood-supply to the affected joint ; $(b)$ Free drainage for pus.

3. The practical requirements of the treatment are : (a) Free outlets for fluid from the joint; (b) Active movements.

4. In about 50 per cent of the cases treated a useful mobile joint has been obtained.

5. In the absence of extensive bone injury - which necessarily negatives this treatment-provided the physiological method is established early, resolution is hastened and tracking is rare. Collections of pus in the popliteal space occur frequently.

6. The method is impracticable if its adoption be delayed until the establishment of the fulminating stage of suppurative arthritis. 


\section{THE BRITISH JOURNAL OF SURGERY}

Table of Cases treated by the Physiological Method.

\begin{tabular}{|c|c|c|c|c|c|c|c|c|c|}
\hline $\begin{array}{l}\text { CASE } \\
\text { No. }\end{array}$ & \multicolumn{2}{|l|}{ ORGANISMS } & \multicolumn{3}{|c|}{ BONE INJURY } & $\begin{array}{l}\text { EXTRA-AHTICULAR } \\
\text { SUPPURATION }\end{array}$ & \multicolumn{2}{|c|}{$\mid \begin{array}{c}\text { DAY WHEN } \\
\text { AQTIVE } \\
\text { MOVEMENTS } \\
\text { BEGAN }\end{array}$} & RESULT \\
\hline 1 & $\begin{array}{l}\text { Staphylococeus .. } \\
\text { Streptococeus (long chain) }\end{array}$ & & Fernur & . & . & *'Thigh, aborted & 11th & day & Ankylosis \\
\hline 2 & $\begin{array}{l}\text { Staphylococcus .. } \\
\text { Streptococcus (long chain) }\end{array}$ & & Femur & $\cdots$ & $\cdots$ & $\begin{array}{l}\text { *Thigh, aborted } \\
\text { Popliteal }\end{array}$ & 15th & ", & Ankylosis \\
\hline 3 & $\begin{array}{l}\text { Staphylococcus } \\
\text { Streptococcus }\end{array}$ & . & Tibia and & ella & $\cdots$ & $\begin{array}{l}\text { *Thigh, aborted } \\
\text { Popliteal }\end{array}$ & 10 th & ", & Ankylosis \\
\hline 4 & $\begin{array}{l}\text { Diphtheroids } \\
\text { Streptococeus (short chain }\end{array}$ & & Femur & $\cdots$ & . & - & 7 th & " & $90^{\circ}$ mobility \\
\hline 5 & $\begin{array}{l}\text { Staphylococcus } \\
\text { Streptococcus }\end{array}$ & - & None & . & $\cdots$ & Popliteal . . & 5 th & " & $105^{\circ}$ \\
\hline 6 & $\begin{array}{l}\text { Staphylococeus } \\
\text { Streptococcus }\end{array}$ & $\cdots$ & Femur & . & . & 一 & 4 th & , & $90^{\circ}$ \\
\hline 7 & $\begin{array}{l}\text { Staphylococcus } \ldots \\
\text { Coliform bacillus }\end{array}$ & $\cdots$ & Tibia, fen & and & & - & 6 th & " & $60^{\circ}$ \\
\hline 8 & $\begin{array}{l}\text { Staphylococcus . . } \\
\text { Streptococcus (long chain }\end{array}$ & & Fibula & $\cdots$ & . & Popliteal $\cdot$. & 4th & , & Amputation \\
\hline 9 & Staphylococeus .. & . & Patella & . & . & Popliteal .. & 5 th & , & Ankylosis \\
\hline 10 & $\begin{array}{l}\text { Staphylococcus } \\
\text { Streptococcus }\end{array}$ & $\ldots$ & Femur & . & . & Popliteal .. & lith & , & Ankylosis \\
\hline 11 & $\begin{array}{l}\text { Staphylococeus } \\
\text { Coliform bacillus }\end{array}$ & .. & Femur & . & .. & $\begin{array}{l}2 \mathrm{in.} \mathrm{up} \mathrm{from} \\
\text { external ar- } \\
\text { throtomy } \\
\text { wound }\end{array}$ & 10 th & , & Ankylosis \\
\hline 12 & Staphylocoecus .. & .. & Tibia .. & . & . & Popliteal $\quad$. & 6 th & , & Ankylosis \\
\hline 13 & $\begin{array}{l}\text { Staphylococcus } \\
\text { Streptococcus }\end{array}$ & .. & Patella & . & . & $\begin{array}{l}\text { Suppurating } \\
\text { hæmatoma } \\
\text { of thigh }\end{array}$ & 9th & ", & Ankylosis \\
\hline 14 & Staphylococcus .. & $\cdots$ & None & . & . & - & 7th & 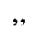 & Full mobility \\
\hline 15 & $\begin{array}{l}\text { Streptococcus } \\
\text { Coliform bacillus }\end{array}$ & . & Femur & . & . & - & 4 th & , & $45^{\circ}$ mobility \\
\hline 16 & $\begin{array}{l}\text { Staphylococcus .. } \\
\text { Coliform bacillus }\end{array}$ & $\cdots$ & Patella & . & . & Popliteal & 5 th & , & Ankylosis \\
\hline 17 & $\begin{array}{l}\text { Staphylococcus } \\
\text { B. Welchii }\end{array}$ & $\cdots$ & Femur & . & . & - & 5 th & ", & Full mobility \\
\hline 18 & B. Welchii & . & Patella & . & . & 一 & 7 th & , & Full mobility \\
\hline 19 & B. Welchii & $\cdots$ & Femur & . & . & - & 3rd & $"$ & Full mobility \\
\hline 20 & Streptococeus (long chain) & & Tibia . . & .. & . & Popliteal & 4th & , & Ankylosis \\
\hline 21 & Staphylococcus .. & $\cdots$ & Femur & . & . & -- & 7 th & $"$ & $50^{\circ}$ mobility \\
\hline 22 & Staphylococcus .. & $\cdots$ & None & $\cdots$ & . & - & 6th & ", & Full mobilitty \\
\hline 23 & Streptococcus (long chain) & & Femur & $\cdots$ & - & -- & 13th & " & Ankylosis \\
\hline
\end{tabular}

$*$ By this is meant that at the time of my original operation pus had extended throush the subcrural bursal reflection, $N o$ further tracking ensued.

\section{REFERENCES.}

1 Everidge, Brit. Med. Jour., 1918, Aug. 28.

2 Willems, Comptes Rendus de la Conférence Interalliée pour l'Etude des Plaies de Guerre, 1917, Nov.

3 Gosset, Ibid., March.

4 Lazarus Barlow, Brit. Med. Jour., 1916, Dec. 30.

5 VeIllon, Comptes Rendus de la Conférence Interalliée pour l'Etude des Plaies de Guerre, 1917, March.

6 Lockwoon, Brit. Med. Jour. 1916, Jan. 29.

7 GraY, Ibid., 1915 , July 10.

8 Carrec, Le Traitement des Plaies Infectées. 